\title{
THE EFFECTIVENESS OF EMPLOYEE PERFORMANCE APPRAISAL SYSTEM IN HEALTH SECTOR: EVIDENCE FROM IRANIAN ORGANIZATIONS
}

\author{
Abbas Homauni, Ali Mohammad Mosadeghrad, Ebrahim Jaafaripooyan
}

Department Of Health Economic and Management, School Of Public Health And Institute Of Public Health Research, Tehran University Of Medical Sciences, Tehran, Iran

Correspondence: jaafaripooyan@tums.ac.ir

\begin{abstract}
INTRODUCTION:

Performance appraisal is a formal process to review and improve the organizational performance of employees regularly. Despite the appropriate organizational frameworks for performance appraisal, they are not apparently addressing the operational realities of health care organizations. This study thus aimed to examine the effectiveness of the current performance appraisal system of employees at Tehran University of Medical Sciences (TUMS) from the perspective of employees.
\end{abstract}

\section{METHODS:}

The data were collected from 504 TUMS employees using researcher-developed questionnaire following the validation. It consisted of 46 questions covering such various dimensions as performance expectations, communication of performance objectives to employees, self-assessment, performance metrics, surveyors, and performance appraisal results. ANOVA, t-test, Post hoc and Tukey statistical tests were used during analysis process by SPSS 22.

\section{RESULTS:}

The performance appraisal system was not found as effective as expected from the employees' perspective and the scores for all its dimensions dropped below the average. The overall performance appraisal score was 2.71 (out of 5). There was also a significant correlation between the employees' education and organizational job group and the score of performance appraisal $(p<0.0001)$.

\section{CONCLUSION:}

The current appraisal system according to the results is not well functioning. Therefore, it seems necessary to make urgent changes. The lack of active participation from employees and managers in performance appraisal development process, and the subsequent low motivation to improve their performance seems to be a persistent challenge. A fairly desirable solution might be to decentralize the appraisal processes rendering more authority to managers and supervisors along with empowering managers.

\section{KEYWORDS}

Performance appraisal; Effectiveness; Health system. 
Health care organizations (HCOs) play a crucial role in societies, as each individual might visit one of these organizations during their lifetime, even before "the cradle to the grave". These organizations employ a variety of financial, human, information, structural and technological resources. Manpower is inter alia considered as "dominant resources" as they are intelligent, trainable, can utilize and optimize the use of other resources and cannot be easily set aside and moved. [1]

Human resources (HRs) contribute substantially in providing health services to society, and are deemed as the best competitive advantage for organizations. In fact, employees are the costliest resource of HCOs whose activities are highly required to be aligned with the mission of such organizations. Serious focus on the competency boost of employees and improving their performance can significantly enhance the performance of organizations. [2, 3] Human resource management (HRM) in HCOs is apparently essential for promoting efficient and effective services and customer satisfaction, [4] as well as achieving better results regarding the health system performance and also people's access to quality health services. $[5,6]$ Employee performance appraisal (EPA), a key step in HRM cycle, is given special attention in modern management. It is said to be more important than financial management, [7] hence, needs to be under continuous scrutiny especially when the outcome of health system is related to life and health. EPA is a 'formal process by which the work activities of organizations' employees are regularly reviewed and evaluated'.[8] It is fundamental within the complex HRM practices, and stands as a prerequisite for other activities such as feedback, rewarding and punishment, staff development and training in organizations. [9] Proper evaluation of employees' performance through measuring, monitoring, and creating a system of selfcontrol and self-assessment, might have a very crucial role in improving their accountability and ultimately in the improvement of organizational performance. [10, 11] The main purpose of performance appraisal in $\mathrm{HCO}$ is also to monitor performance, boost employee motivation and ultimately improve the overall performance of organization resulting in an increase in the patient satisfaction. [12] In addition, performance appraisal can be useful in designing an educational system to address employee weaknesses as well as in developing an incentive and punishment system.

The poor performance of health system staff may threaten life of people or at least adversely affect their health. Therefore, existence of a well-designed performance appraisal system in HCOs is a compelling need, and performance of employees should be monitored and rectified professionally and regularly. [13]

There are some methods that have been proposed to evaluate employee performance such as the rating scale, grading, reporting sensitive events, management-byobjectives (MBO), checklists, talking and listening, and 360 degree evaluation method. [14]

\section{EPA SYSTEM IN THE IRANIAN HEALTH SYSTEM}

Ministry of Health $(\mathrm{MOH})$ is the main body responsible for the process of appraising employee performance in the country. It is practically entrusted to the medical universities, placed under the deputy for resource planning and development, within the purview of the administrative transformation office.

All non-academic staff working in the public HCOs are annually appraised. The jobs are classified into six groups under which, several professions exist; including, information technology, social, financial and administrative, culture and education, health care and engineering. It should be noted that health care category encompasses the largest number of employees, followed by the financial and administrative group among the employees. The EPA has been recently modified. It has become fully electronic, and employees could partly provide suggested indicators for their performance appraisal.

The performance measurement indicators are divided into two categories; general and specific, representing for 100 score points overall; 60 points for general indicators and 40 for specific indicators. General indicators are similar for all job groups representing mainly initiative and innovation, education and training and customer satisfaction. Specific indicators, instead varies depending on the tasks, requirements and qualifications of different job groups.

A study showed that organizational context of public hospitals is now more convenient and receptive to performance appraisal, however, the system itself does not reflect the realities at hospitals [15]. It also found that the existing EPA was ineffective and could not measure the actual staff performance. Despite the great importance of employees' performance evaluation in achieving 
organizational goals, it is suffering from some flaws in the HCOs, including mainly; the centralized metric development, lack of attention to the work results and poor performance measurement. [15] Therefore, the purpose of this study was to measure the perceived effectiveness of the current performance appraisal system in accordance to the perspective of employees at TUMS.

\section{METHODS}

This descriptive-analytical, cross sectional study was conducted in 2020. The research population included all permanent and contracted employees working in the hospitals, schools, deputies and health care centers of TUMS, the biggest university in the country which is under the auspices of the $\mathrm{MoH}$.

According to this formula and considering $N=14000$ and $95 \%$ confidence interval and $d=0.05$ and $p$ and $q$ equal to 0.5 , the sample size was calculated 373 .

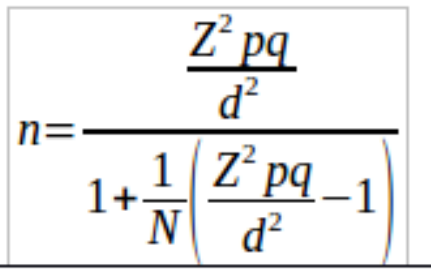

Given the clustering strategy in the sampling, this number was multiplied by 1.2 as a cluster coefficient and finally the sample size was calculated 448. However, we distributed 610 to avoid the possible attrition, which around 501 questionnaires returned (response rate=82.1\%).

Due to the fact that staff of TUMS are divided into six general job categories including; information technology, social, financial and administrative, culture and education, health care and engineering, the ratio was considered per category, and the questionnaires were distributed among employees accordingly. Therefore, 317 questionnaires were handed to health care workers, 97 to financial and administrative, 49 to social and culture and education, and 40 questionnaires to information technology and engineering employees.

A researcher developed and administered questionnaire was utilized for data collection. It consists of two main parts: employees' sociodemographic characteristics including organization name, age, sex, marital status, education, work experience, job group and employment status. The second part contained 46 questions on the various dimensions of EPA system; performance expectations (8 questions), communication of performance expectations to employees (2 questions), self-assessment (4 questions), performance metrics (10 questions), measurement (5 questions), time and feedback (4 questions), surveyors (3 questions), performance appraisal output (4 questions), performance appraisal outcome (5 questions) as well as a question on the staff general evaluation of' EPA system. Some questions include 'I take the EPA serious, EPA results matter for the managers, EPA is a fair system. A five-point Likert-type scale was used; from the complete agreement scoring 5 till complete disagreement with score 1.

In the validation process of questionnaires, the content validity index (CVI) and content validity ratio (CVR) were calculated (0.89 and 0.61 , respectively), to represent the importance, simplicity, relevance and clarity of each question, seeking the relevant experts' views; including hospital managers, nursing managers, human resources managers (all with at least five years of job experience) and subject matter experts in HRM. As such, for its reliability, a pilot study of 20 employees was conducted at 2-week intervals on the basis of test-retest, then, $\mathrm{R}$ was 0.89 .

Prior to completing questionnaires, the study objectives and questionnaire content were briefly explained to the staff members, and the questionnaire was handed if they were willing to take part. It is noteworthy that a total of 610 questionnaires were distributed, and 501 were completed and included for analysis. SPSS (version 22.0) was used for analysis by applying ANOVA, t-test, Post hoc and Tukey statistical tests. The significance level was under 0.05 .

\section{RESULTS}

Out of the 501 participants, the majority was female (82.2\%). In terms of academic degree, $71.1 \%$ had bachelor's degree and $22.8 \%$ had master degree or higher. More than $55 \%$ of respondents had work experience between 6 and 15 years. Regarding job group, most people were from health care category (63\%). About $44 \%$ were formal employees, roughly $41 \%$ were on formal contract-based work and the rest were informal contract workers, and finally, most of the participants (about 25\%) were in the age range of 36 to 40 years (Table 1). 


\begin{tabular}{|c|c|c|c|}
\hline VARIABLE & CATEGORY & NUMBER & PERCENTAGE \\
\hline \multirow{4}{*}{ Education } & Above diploma & 30 & 6 \\
\hline & BSC & 352 & 70.3 \\
\hline & Postgraduate & 113 & 22.6 \\
\hline & No answer & 6 & 1.1 \\
\hline \multirow{7}{*}{$\begin{array}{l}\text { Work experience } \\
\text { (years) }\end{array}$} & $0-5$ & 62 & 12.4 \\
\hline & $6-10$ & 139 & 27.7 \\
\hline & $11-15$ & 135 & 26.9 \\
\hline & $16-20$ & 71 & 14.2 \\
\hline & $21-25$ & 49 & 9.8 \\
\hline & $>25$ & 38 & 7.6 \\
\hline & No answer & 7 & 1.4 \\
\hline \multirow{4}{*}{ Job group } & Health care & 316 & 63.1 \\
\hline & Financial -administrative & 96 & 19.1 \\
\hline & Culture-education & 49 & 9.8 \\
\hline & IT and engineering & 40 & 8 \\
\hline \multirow{4}{*}{ Job nature } & Permanent & 185 & 36.9 \\
\hline & Contract (formal) & 60 & 12 \\
\hline & Contract (informal) & 174 & 34.7 \\
\hline & No answer & 82 & 16.4 \\
\hline \multirow{6}{*}{$\begin{array}{l}\text { Age } \\
\text { (years) }\end{array}$} & $\leq 30$ & 107 & 21.3 \\
\hline & $31-35$ & 109 & 21.8 \\
\hline & $36-40$ & 125 & 24.9 \\
\hline & $41-45$ & 85 & 17 \\
\hline & $46-50$ & 52 & 10.4 \\
\hline & $>50$ & 23 & 4.6 \\
\hline
\end{tabular}


TABLE 2: PERCEIVED EFFECTIVENESS OF THE EPA DIMENSIONS

\begin{tabular}{|lll|}
\hline DIMENSION OF EPA & $\begin{array}{l}\text { MEAN } \\
\text { (OUT OF }\end{array}$ & $\begin{array}{l}\text { STANDARD } \\
\text { DEVIATION }\end{array}$ \\
\hline Performance expectations & 2.85 & 0.92 \\
Communicating performance objectives & 2.83 & 1.01 \\
Self-assessment & 2.74 & 0.96 \\
Performance appraisal indicators & 2.74 & 0.84 \\
Performance measurement & 2.6 & 0.88 \\
Time and feedback & 2.73 & 0.94 \\
Surveyors & 2.97 & 1.08 \\
Performance appraisal output & 2.52 & 0.98 \\
Performance appraisal results & 2.42 & 0.98 \\
Overall assessment & 2.71 & 0.82 \\
\hline
\end{tabular}

Table 2 shows mean and standard deviation for different dimensions of performance appraisal from perspective of study respondents.

The highest score among EPA dimensions is associated with "surveyors" (mean $=2.97$ ), while the lowest score was related to the dimension of performance evaluation results (mean = 2.42). Interestingly, the effectiveness of all dimensions of performance appraisal system was below the average (maximum score 5, minimum 1 and average score 3).

The participants' perceptions toward the performance of EPA were significantly different in terms of their education level and job group (table 3).

doluptat.

TABLE 3. THE PARTICIPANTS' PERCEIVED EFFECTIVENESS OF EPA AND THEIR EDUCATION AND JOB GROUP

\begin{tabular}{|lllll|}
\hline VARIABLE & CATEGORY & MEAN & SD & P-VALUE \\
\hline \multirow{2}{*}{ Educational } & Upper-diploma & 126.44 & 39.37 & \\
level & BSC & 116.76 & 36.85 & $<0.0001$ \\
& Postgraduate & 137.52 & 32.14 & \\
\hline \multirow{2}{*}{ Job group } & Health care & 113.70 & 36.66 & \\
& Financial -administrative & 140.89 & 33.90 & \\
& Culture-education & 130.07 & 25.41 & $<0.0001$ \\
& IT and engineering & 131.60 & 37.12 & \\
\hline
\end{tabular}


According to the table, the average score of perceived effectiveness of EPA in postgraduates was 137.5, the highest rate compared to the participants from other educational levels. As such, the differences in the perceived effectiveness of the appraisal system in terms of job category were also statistically significant ( $p$-value $<0.0001)$. The highest mean score belonged to the

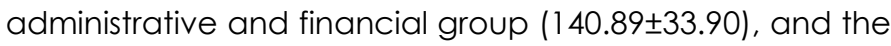
lowest to the health care group (113.70 \pm 36.66$)$.

In terms of the participants' age, work experience, job group and marital status, no significant relationship was found among their views on the effectiveness of EPA.

\section{DISCUSSION}

This study aimed to evaluate the effectiveness of the EPA system at TUMS. To this end, the perspective of employees was elicited on the EPA's nine dimensions including; the EPA's performance expectations, communicating expectations, self-assessment, metrics, performance measurement, time and feedback, surveyors, appraisal output and outcomes.

AMO (ability, motivation and opportunity) theory is the basic framework for explaining employee performance in organizations. [16] It simply and operationally provides the possibility for diagnosing poor performance of employees in the organization, and implies the underlying ways of improvement. Moreover, several other variables such as employee personality, external expectations, organizational culture, commitment and work conscience of employees, nature of work and environment might affect the level of employee performance and serve as a workable framework for performance evaluation. [17-19] Therefore, the effectiveness of an EPA system can highly depend on the accurate measurement of these variables and their relationships. This is crucial as performance appraisal could serve as an employee motivational process affected by the interactions between employees and their managers. [20] Drawing on the findings, it seems that the organizational climate in the organizations is not suitable or the assessment relationship between the employees and managers as their first supervisor is questionable. This might be partly attributed to the lack of managers' significant role in designing evaluation indicators of the employee performance, and also the shortage of their enough power and capacity to utilize the results of performance evaluation. Therefore, employees briefing upon their performance appraisal objectives, in line with Drucker's theory of management by objectives, has not been apparently shaped and subsequently employee feedback on performance not sought. [21] As such, the employees are not aware of the real effect of performance appraisal on their performance, and do not recognize the consequences of their desirable or poor performance, even though, regardless of the principle of objectivity in performance appraisal. The good-performing employees in such situations might lose their momentum in maintaining or improving their performance. [22] If organizations simply use a top-down approach to setting the appraisal goals, this is likely to reduce the employee participation and motivation and cause resistance towards the performance appraisal, [23] while the modern approaches are demanding more involvement and participation from various groups. The 360-degree or 720 degree, as decent modern examples, allow for evaluation, once and twice respectively, by peers, subordinates, managers, internal and external customers of organization and, if possible, by suppliers. [24] This is poorly attended in the current EPA. For example, the patients' satisfaction or complaints about employees such as nurses, laboratory staff and imaging technicians could be assimilated in their performance appraisal scores. A recent relevant study indicated that current appraisal system is mostly causing discouragement, indifference or even hostility in the workplace, instead of encouraging and nurturing the abilities and thoughts of the employees. It also should that the staff were unaware of the purpose of performance appraisal. [15] Furthermore, the performance expectations and goals were not properly communicated to employees alluding to the paucity of a dynamic interaction between the employees and their manager or supervisor undermining their participation in performance appraisal process. Roberts points to the importance of employee participation in performance appraisal and its strong association with the high levels of employee satisfaction and their receptivity of appraising [25]. Buchelt also reiterates the importance of employee participation in EPA. [26]

The link between rewards and one's performance, neglected in the current system, is key in the effectiveness of EPAs [21] as it is providing feedback to the employees of their performance. [27] Feedback is more effective when it is provided regularly, objectively, and also given shortly after appraisal. In 'no feedback' situations the goodperforming employees might get demotivated, and those of poor performance will persist. Choudhary and Puranik 
similarly stressed on the flexibility and appropriateness of EPA for HCOs, clarity of its goals, well development of its indicators and continuous feedback on employee performance. [27] Performance appraisal indicators are considered as the core of EPAs. They were perceived as inappropriate and incompatible which might be partly as they were mostly developed centrally with minimum involvement of staff. They described as subjective and incompatible with the realities of jobs. Rolle and Klinger [28] mention subjectivity of evaluation indicators, overdocumentation and also the abuse of performance evaluation results as a tool for punishing employees as the most prominent challenges faced by EPAs. Most of the participants complained about their unawareness of indicators, assessment methods and the subsequent use of their appraisal results and feedback.

The most challenging and critical step in EPA is measuring the actual performance of employees. Standardized measurement instrument including valid and objective metrics and oriented and fair assessors are key for this stage. Employees de facto need to recognize that the measurement and scoring are fair. The participants were dissatisfied with this dimension and assigned low score. Some supervisors might be more strict and conservative and subsequently evaluate their employee harshly leading into perceived unfairness. Therefore, the supervisors and surveyors are recommended to be entirely trained and oriented. Equity theory also postulates the fact that employees always compare their outputs and throughputs with their peers. [29] Gregorodis proposes the use of normal distribution diagrams for a united and fair evaluation of employees. [13]

Highly educated employees obtained higher appraisal score and were more satisfied with the performance appraisal. This might be because of the education and research related performance indicator from which they could easily earn higher score. Besides, the career development and promotion was available for welltrained, qualified and higher-educated staff.

Overall, our results consistent with few similar studies dare to indicate that the current system is not functioning well. It further agree with Zaboli et al. arguing that if this process is continued as in the past and present, it might reduce the employees' motivation and even increase their hostility in the workplace. [15]

The key limitation of study was the hesitation and reluctance of employees to participate in the research, due to their concerns over the effect of their opinions on their performance appraisal score, which was almost resolved by the explanations and reassurance provided by the researcher to keep the confidentiality and privacy high.

\section{CONCLUSION}

Performance appraisal is a critical step in HRM that, if done properly, is highly expected to improve employee and ultimately organizations' performance. Evidently, an EPA is more likely to be effective and taken serious, among all, if those are assessed have some 'say' and feedback in its development and implementation. Moreover, it is of a firm link with employees' career and payment system. Otherwise, these system could easily turn into some sort of 'formality' inside organizations. Centralized EPAs might kill the incentives for improvement, thus room for contextualized flexibility for those organizations whose employees are assessed is recommended.

The current system suffered to a large extent from several challenges. Most of the employees and organizations did not recognize the importance of performance appraisal and even care about. They were clearly not involved in performance appraisal process, and were not given feedback on evaluation results. Managers and supervisors also did not possess the adequate authority and capacity to use the results of performance appraisal due to the centralized system of appraisal. Performance-based assessment and payment is a key 'way forward' in developing effective EPAs.

Despite improvements that have been made in recent years to enhance the quality of performance appraisal indicators, they have not been able to serve the specific objectives related to each job.

With all costs and efforts put into employees' appraisal, there should be always a serious concern upon and regular scrutiny and refinement of the effectiveness of in action appraisal systems among policy makers and managers.

\section{ACKNOWLEDGEMENTS:}

This research has been supported by Tehran University of Medical Sciences and Health Services grant 96-06-1440543. We are grateful to the study participants for their time and viewpoints.

\section{CONFLICT OF INTEREST:}

The authors have no conflict of interest to declare. 


\section{ETHICAL CONSIDERATION:}

Ethical approval for this study was obtained from the research ethics committee of Tehran University of Medical Sciences On March 13, 2018 (number: 4826). Informed consent was obtained from all participants before the study, and identification information was not used during data analysis.

\section{FUNDING INFORMATION}

Tehran University of Medical Science and Health Services grant 96-06-14- 40543

\section{References}

1. Muthuku M. Soft HRM Model: Human Capital as the Greatest Asset for Organizational Performance. Journal of Human Resource \& Leadership. 2020;4(2):14-29.

2. Vainieri M, Ferre F, Giacomelli G, Nuti S. Explaining performance in health care: How and when top management competencies make the difference. Health care management review. 2019;44(4):306.

3. Song H, Tucker A. Performance improvement in health care organizations. Foundations and Trends ${ }^{\circledR}$ in Technology, Information and Operations Management. 2016:9(3-4):153-309.

4. Elarabi HM, Johari F. The impact of human resources management on healthcare quality. Asian journal of management sciences \& education. 2014;3(1):13-22.

5. Bibi M. Linkage between performance of healthcare professionals and management practices in health care organizations. JPMA The Journal of the Pakistan Medical Association. 2021;71 (2 (B)):725-9.

6. Patri R, Suresh M. Modelling the enablers of agile performance in healthcare organization: a TISM approach. Global Journal of Flexible Systems Management. 2017;18(3):251-72.

7. Kundu PK. Performance Evaluation of Hospital Employees through Ongoing Appraisal Systems. International Journal of Thesis Projects and Dissertations. 2015;3(2):19-27.

8. Parsa M, Shahandeh A, Kamali A, Naji B, Sami M. Offering Two New Methods for Employees' Performance Appraisal (Case Study: Iran Aircraft Manufacturing Company). International Journal of Industrial Engineering. 2013;24(3):377-93.

9. Stewart GL, Brown KG. Human resource management: John Wiley \& Sons; 2019.
10. Colton D. Strategies for implementing performance measurement in behavioural health care organisations. Journal of Health Management. 2007;9(3):301-16.

11. Lutwama GW, Roos JH, Dolamo BL. Assessing the implementation of performance management of health care workers in Uganda. BMC health services research. 2013;13(1):355.

12. Brefo-Manuh AB, Anlesinya A. Performance appraisal justice and work attitudes of health-care workers in Ghana. European Journal of Training and Development. 2021.

13. Grigoroudis E, Zopounidis C. Developing an employee evaluation management system: the case of a healthcare organization. Operational research. 2012;12(1):83-106.

14. Apak S, GümüşS, Öner G, Gümüş HG. Performance appraisal and a field study. Procedia-Social and Behavioral Sciences. 2016;229:104-14.

15. Zaboli R, Delgoshaei B, Haghani H. Assessing the performance appraisal system at general hospitals affiliated with Iran University of Medical Sciences, 2004-2005. Journal of Health Administration. 2005;8(21):117-22.

16. Marin-Garcia JA, Tomas JM. Deconstructing AMO framework: A systematic review. Intangible Capital. 2016;12(4):1040-87.

17. Eliyana A, Ma'arif S. Job satisfaction and organizational commitment effect in the transformational leadership towards employee performance. European Research on Management and Business Economics. 2019;25(3):144-50.

18. Indarti S, Fernandes AAR, Hakim W. The effect of OCB in relationship between personality, organizational commitment and job satisfaction on performance. Journal of Management Development. 2017.

19. Kawiana IGP, Dewi LKC, Martini LKB, Suardana IBR. The influence of organizational culture, employee satisfaction, personality, and organizational commitment towards employee performance. International research journal of management, IT and social sciences. 2018;5(3):35-45.

20. Rusu G, Avasilcăi S, Huțu C-A. Organizational context factors influencing employee performance appraisal: A research framework. Procedia-Social and Behavioral Sciences. 2016;221:57-65. 
21. Idowu A. Effectiveness of performance appraisal system and its effect on employee motivation. Nile Journal of Business and Economics. 2017;3(5):15-39.

22. Longenecker $C$, Fink L. Lessons for improving your formal performance appraisal process. Strategic HR Review. 2017.

23. Chanjaruporn F, Prasert V, Anuratpanich L, Sooksriwong $C$. Evaluation of drug management competency: A comparison between the 360-degree appraisal and manager assessment. Mahidol Univ J Pharm Sci. 2016;43(4):165-72.

24. Aggarwal A, Thakur GSM. Techniques of performance appraisal-a review. International Journal of Engineering and Advanced Technology (IJEAT). 2013;2(3):617-21

25. Roberts GE. Employee performance appraisal system participation: A technique that works. Public personnel management. 2003;32(1):89-98.

26. Buchelt B. Performance Management as Modern Approach to Employees' Appraisal in Healthcare Entities. Education of Economists \& Managers/Edukacja Ekonomistow i Menedzerow. $2011 ; 22(4)$.

27. Choudhary G, Puranik S. A study on employee performance appraisal in health care. Asian J Manag Sci. 2014;2(3):59-64.

28. Rolle C, Klingner D. Performance appraisal systems as a strategic human resource management tool in the Bahamian public service. International Journal of Public Administration. 2012;35(5):303-14.

29. Kollmann T, Stöckmann C, Kensbock JM, Peschl A. What satisfies younger versus older employees, and why? An aging perspective on equity theory to explain interactive effects of employee age, monetary rewards, and task contributions on job satisfaction. Human Resource Management. 2020;59(1):101-15. 